\title{
Liter Per Minute Per Square Meter
}

National Cancer Institute

\section{Source}

National Cancer Institute. Liter Per Minute Per Square Meter. NCI Thesaurus. Code C105496.

A unit expressed as one liter of volume per unit of time equal to one minute per square meter of area. $(\mathrm{NCl})$ 